\title{
Development and Application of FCF Construction Method
}

\author{
Muneyoshi Matsuo*,Syouichi Morimoto*, Yuzuru Sekihara* \\ Hiroto Nemoto**,Masahiko Sawaguchi** \\ * Machine Development Section,Machinery Department,Civil Engineering Division, \\ Fujita Corporation (e-mail : mmatsuo@fujita.co.jp ) \\ 1-15-6,Honda,Niiza-shi,Saitama Prefecture,352 JAPAN \\ ** Architectural Construction Division,Tokyo Branch,Fujita Corporation \\ Syuuyoudan Building 4-25-2,Sendagaya Shibuya-ku, Tokyo,151 JAPAN
}

\begin{abstract}
The FCF construction method (Fast Failsafe Climbing Form) with the climbing robot jack as a nucleus, was developed for construction of high-rise concrete structures, such as a tower-shape or a cylindrical tall bridge pier, etc. This construction method uses a plural number of the climbing robot jacks to ascend the whole of the various construction facilities assembled on the main frame for construction of a structure and descends it to the ground surface after the completion of the structure. The main features of the construction method include (1) improvement of safety (2) shortening of construction period and (3) cost reduction. Thus far this method has been introduced to 7 construction sites (12 construction objects) mainly with the aim of construction of tall bridge pier, obtaining favorable results.

As this construction method was advanced further this time to make the working space an all-weather type and by giving various added values thereto we have constructed a chimney of RC construction with $118 \mathrm{~m}$ in height, a high-rise structure. In the text of this report, special features of this system, detailed results of construction of each component system as well as the effectiveness of application of this construction method to the high-rise structure, are described.
\end{abstract}

\section{Introduction}

To perform assembling and disassembling of scaffolding for operation and removal and moving of forms in the construction of a high-rise concrete structure, such as a tall bridge pier, etc., more safely and aiming at reducing manpower so that scaffolding and form work operations can be performed without having to depend on specialty workers compared with conventional total scaffolding method and sliding form method, the development was made incorporating special features of the large form method and the sliding form method.

Thereafter, experiences have been accumulated in the tall bridge pier construction work, based on which a crane was loaded on the climbing system to improve the ability of the climbing robot jack and the system was improved to be an all-weather type with a roof so as to cope with super tall bridge pier and to aim at further improving workability and manpower saving.

\section{Composition and Summary of the Construction Method}

Fig. 1 shows the summary composition of the FCF construction method. On the perimeter of the bridge pier, the main frame, which is a cradle of the system is installed on the perimeter of the structure through the steel pipe rod of $4 \sim 8$ in number ordinarily depending on the size of the main frame. Here, the steel pipe rod plays the role of a support prop as a guide and against the perpendicular load at the time of moving. Each rod is a metal fitting to prevent buckling, which is fixed to the structure at a prescribed spacing.

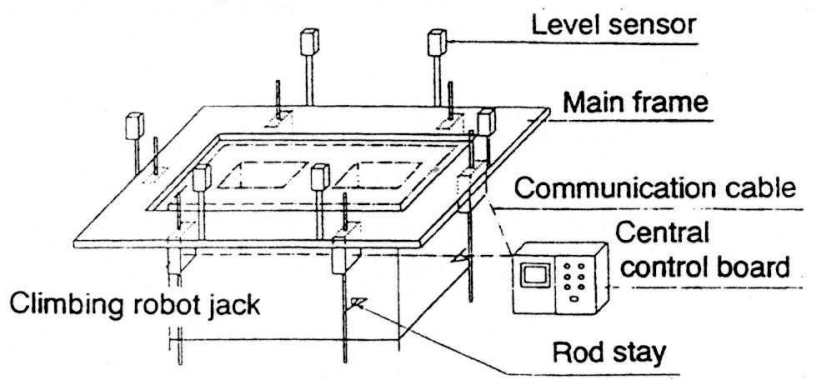

Fig.1 Summary of the FCF construction method Damping of horizontal load (wind load) is accomplished by the roller that is pressed against the structure. Fig. 2 shows the model of the load. On the main frame, the scaffolding for operation is assembled ordinarily in $5 \sim 7$ tiers (approximately $8 \sim 12 \mathrm{~m}$ in length of steel reinforcement) and in addition, a large form (approximately $5 \mathrm{~m}$ in height), a local personal computer 


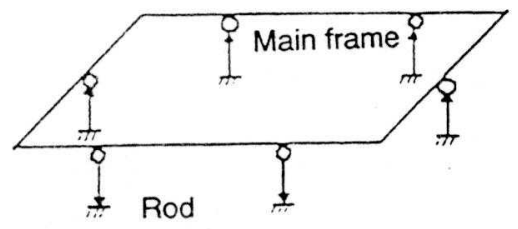

Model of vertical load

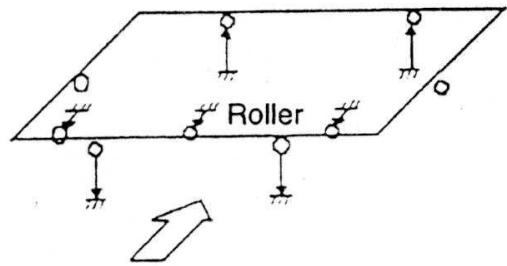

Wind

Model of wind load

Fig.2 Model of the load

that controls the climbing robot jack for ascending and descending and the central control panel that controls the whole of the system, are incorporated. The upper part of the scaffolding for operation, is covered with an automatic open and close roof, constituting the allweather type operation space. At the upper most part of the scaffolding, a crane to lift the construction materials and a distributor that distributes the concrete are laid out. The flat car for conveyance of steel reinforcing bars aims at saving manpower for conveyance. Fig. 3 shows the site of construction of beginning and Fig. 4 the situation of construction.

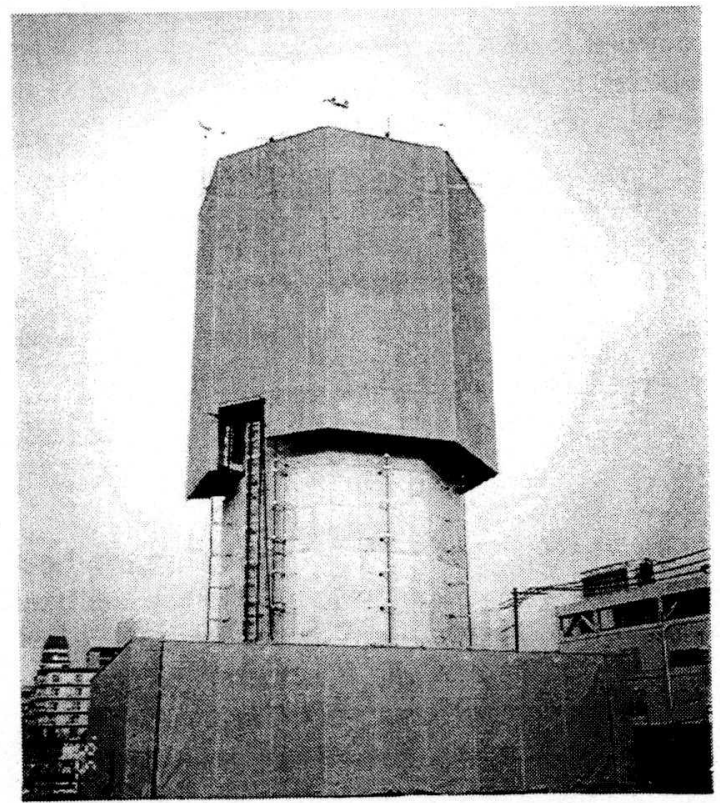

Fig.3 Site of construction of beginning

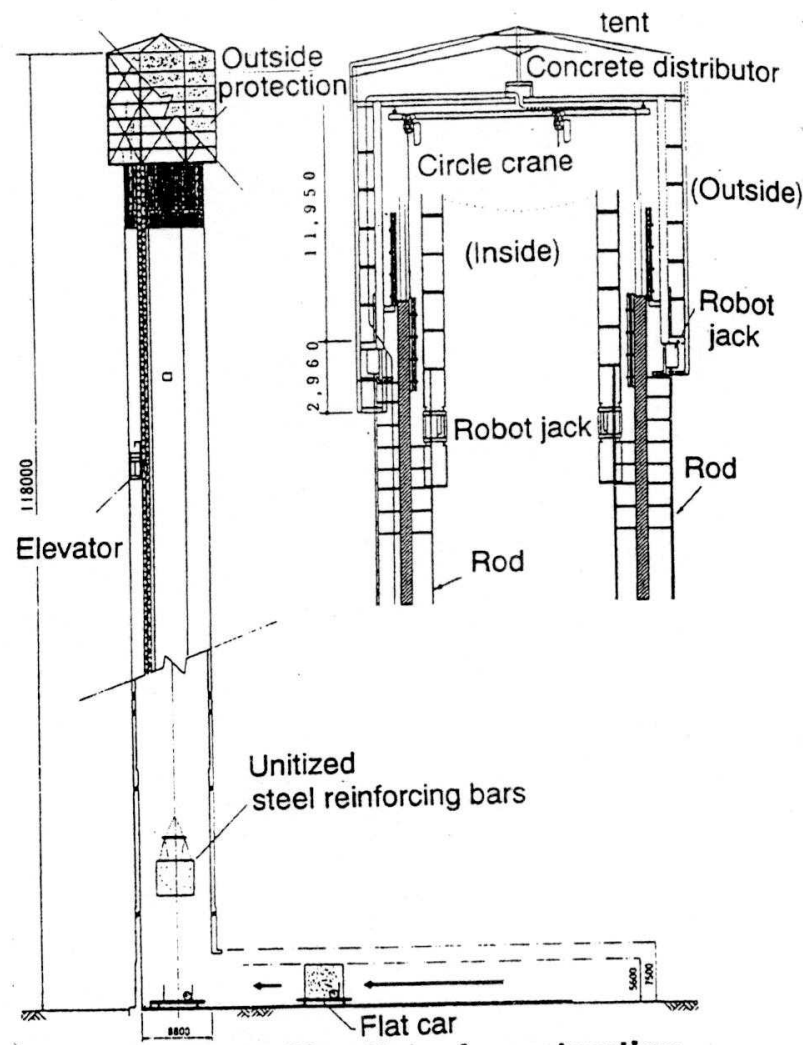

Fig.4 Situation of construction

\subsection{The Climbing Robot Jack System}

This system is composed of the climbing robot jack proper, the central control board and the level sensor. The climbing robot jack proper is composed of the main cylinder, the hydraulic pressure control device, the chuck (grip) device, the local personal computer and various sensors. After the main frame is assembled on the perimeter of the structure to be constructed, a plural number, ordinarily the plural number of approximately 4 $\sim 8$ units of the climbing robot jacks are laid out at the lower part of the main frame. At the center of the climbing robot jack proper, there are two pairs of chuck devices, upper and lower, through which the climbing rod penetrates. Fig. 5 and Fig. 6 show the climbing robot jack and Table 1 the specification thereof.

At the each position where the climbing robot jack is fitted on the main frame, the level sensor is installed, which measures the relative levelness of the main frame by means of the instrumentation of water level. Fig. 7 shows the level sensor.

The local personal computer incorporated in each climbing robot jack transmits the level sensor data and functioning information of the machine proper to the central control board, which in turn computes the difference in level of position of each climbing robot jack, and transmits the control data to the respective local 


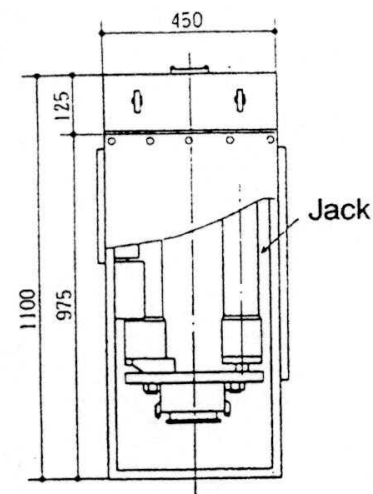

Side

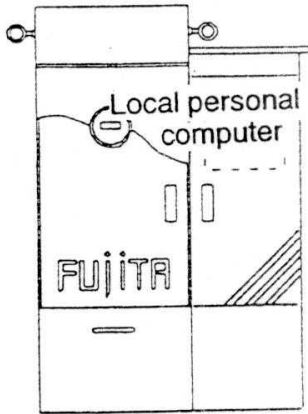

Front
Fig.5 Appearance of climbing robot jack

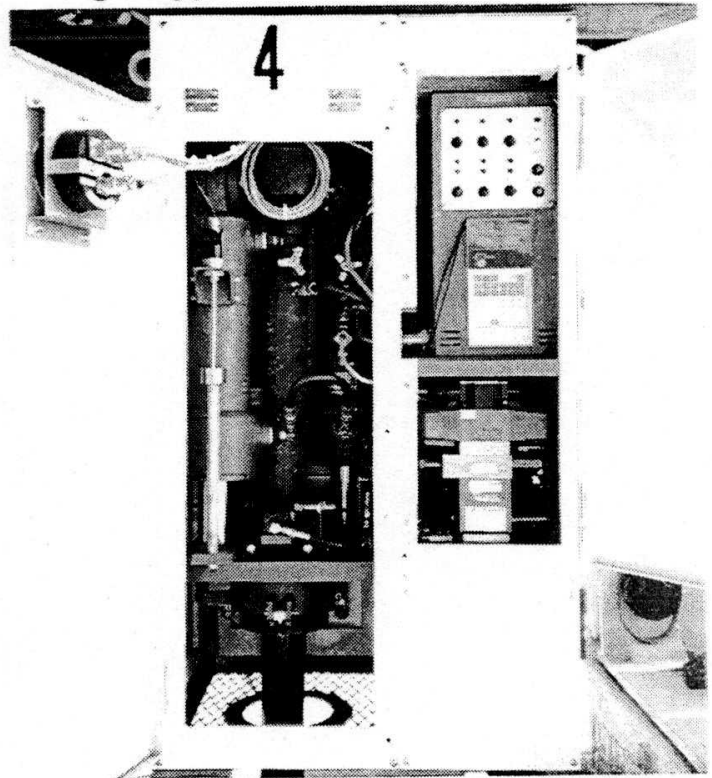

Fig. 6 Body of climbing robot jack

Table.1 Specification of robot jack

\begin{tabular}{|c|c|}
\hline I t e m & specification \\
\hline \multirow{3}{*}{ Ability of equipment } & Force: 15tonf/unit \\
\hline & Max Speed: $31 \mathrm{~cm} / \mathrm{min}$ \\
\hline & Size: $1100 \mathrm{H} \times 620 \mathrm{~W} \times 450 \mathrm{D}$ \\
\hline \multirow[t]{5}{*}{ Oil pressure unit } & Pump:3.51/min (1500rpm) \\
\hline & $4.81 / \mathrm{min}(1800 \mathrm{opm})$ \\
\hline & Pressure:max $140 \mathrm{kaf} / \mathrm{cm}^{2}$ \\
\hline & Motor: $1.5 \mathrm{kw} 4 \mathrm{p}$ 3phase 200v \\
\hline & Tank:20i \\
\hline \multirow[t]{3}{*}{ Oil jack } & Diameter:cylinder90mm,rod50mm \\
\hline & Stroke:200mm \\
\hline & Area:push64cm pull144cm \\
\hline
\end{tabular}

personal computer so as to make this difference in level stays within the allowable range. According to the control data, the local personal computer actuates the respective hydraulic unit and the chuck to grip steel pipe. As a result, this system enables for the main frame and the system thereon to ascend or descend maintaining the allowable difference in level. The stroke of one ascend and descend is $15 \mathrm{~cm}$ and by repeating this action the movement of the prescribed height can be achieved. Fig. 8 shows the central control board and Table 2 the specification thereof. Table 3 shows the specification of local personal computer.

As mentioned above, the climbing robot jack system is the system in which it grips the rod that transmits the reaction force and while maintaining the whole of the main frame horizontally allows the system to ascend and descend. The best features is that it can, not only ascend, but also can descend.

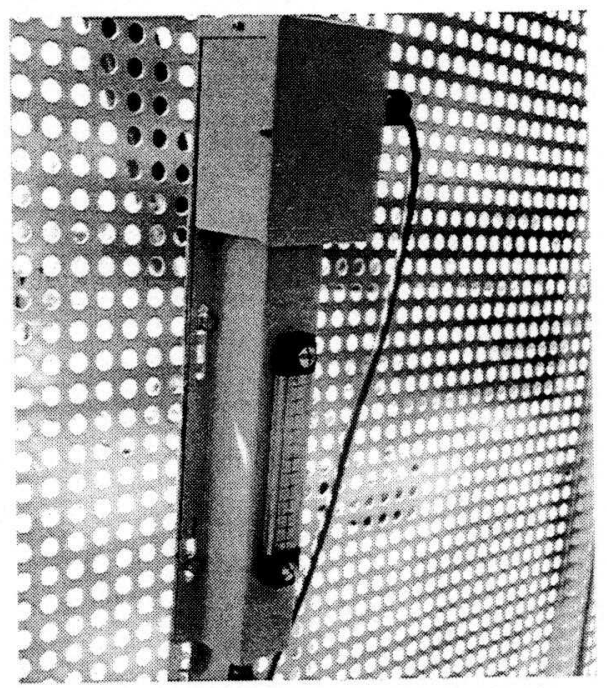

Fig.7 Level sensor

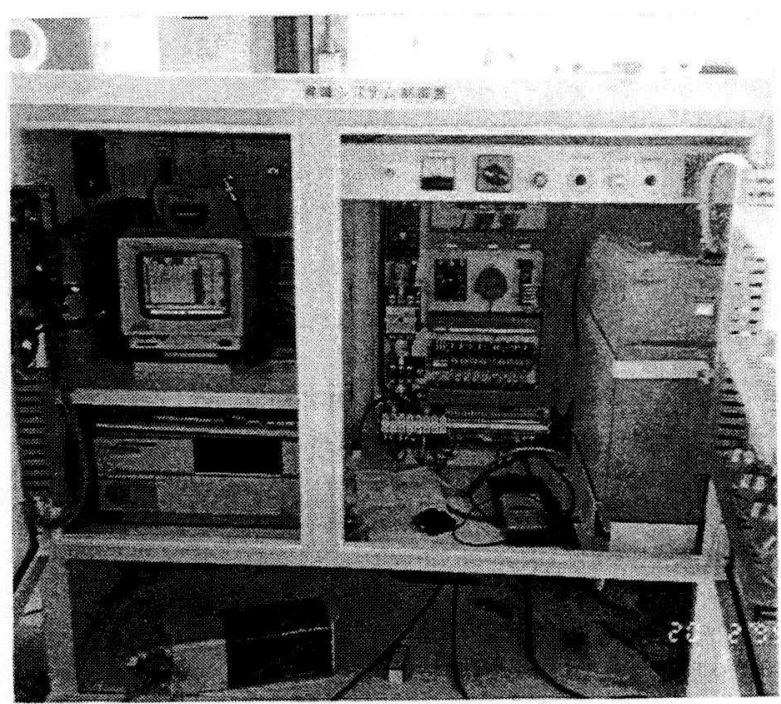

Fig.8 Central control board 
Table.2 Specification of control board

\begin{tabular}{|c|c|}
\hline $\mathrm{tem}$ & specification \\
\hline \multirow[t]{4}{*}{ Computer } & 32 bit cpu \\
\hline & $R A M 1 M$ \\
\hline & HDD $100 M$ \\
\hline & FDD 1 \\
\hline \multirow[t]{2}{*}{ Display } & Touch panel \\
\hline & Graphic display \\
\hline \multirow[t]{3}{*}{ Communication } & Speed 2 Mbps \\
\hline & Max distance $1 \mathrm{~km}$ \\
\hline & Medium: coaxial cable \\
\hline \multirow[t]{2}{*}{ Signal $1 / 0$} & Input 32 point \\
\hline & Output 32 point \\
\hline Sources & 3 phase 3 line $200 \mathrm{~V}$ \\
\hline \multirow[t]{2}{*}{ UPS } & Input $A C 200 V$ \\
\hline & Output AC 1000 \\
\hline
\end{tabular}

Table.3 Specification of local personal computer

\begin{tabular}{|l|l|}
\hline $1 \mathrm{t}$ e $\mathrm{m}$ & specification \\
\hline Sequencer & 16 bit cpu \\
& EEP-ROM \\
\hline Signal input & A C input \\
& D C input \\
& Analog input \\
\hline Signal output & Relay output \\
\hline Communication & Speed $2 \mathrm{Mbps}$ \\
& Medium: coaxial cable \\
\hline
\end{tabular}

\subsection{Hoisting Device}

On the upper part of the working space, for improvement of safety, the circle crane for an exclusive use is set as a hoisting device of construction materials. It is an electric chain block with the lifting capacity of $1.4 \mathrm{t}$ and can cope with $120 \mathrm{~m}$ in the lifting height, which has the turning function of $360^{\circ}$ and can travel sideways, making it effective covering the entire operation area. The operation is by means of a radio controller. The hoisting speed is $6.6 \mathrm{~m} / \mathrm{min}$. at maximum, but as it takes more than 15 minutes when lifting in excess of $100 \mathrm{~m}, 2$ units of electric chain blocks are installed in the system so that the hoisting and descending of the hook can be performed simultaneously.

\subsection{Concrete Distributor}

The structural concrete is conveyed to the construction joint by a concrete pump car and poured insitu. Fur purposes of manpower saving at the time of concrete pouring of the concrete placing operations, a concrete distributor is equipped on the circle crane and making use of the turning function of $360^{\circ}$ of the circle crane the swinging around of piping is mechanized doing away with conventional heavy labor involved thereby achieving manpower saving.

\subsection{Steel Reinforcing Bar Conveyance Flat Car}

Structural steel reinforcing bars used for the structure were assembled on the ground into the mesh bar panel of approximately $1,280 \mathrm{~kg}$ and unitized in advance. This unitized bar is lifted by the circle crane and placed at the location of construction. As a result, number of lifting times of steel reinforcing bars were reduced achieving a large effect. To convey these unitized steel reinforcing bars into the chimney, a motorized conveyance flat car is set at the moving in opening and the unitized steel reinforcing bars are placed vertically on the conveyance flat car in outside and they are moved into the chimney after the lifting has been prepared. By means of this mode, the time for up and down operations in the chimney can be reduced as much as possible, aiming at improving safety and work efficiency.

\subsection{Large Form}

The lightweight form using lumber material was made one large form to each side of the structure to be constructed, which is set on the bracket of the climbing main frame. After the stripping of the form as it ascends with the climbing frame, manpower for erection and stripping operation can be reduced by a large margin.

\subsection{All-weather Type Working Space}

The all-weather type working space that can ascend and descend is constituted on the main frame laid out on the climbing robot jack. These are of structural steel construction and the roof portion is covered with the open and close type tent. The gross height of the working space is approximately $13 \mathrm{~m}$. The working space was assembled on the ground prior to the construction of the structure and was descended to the ground while the finish work was in progress after the structure was completed and disassembled on the ground. This contributed largely to improve safety.

\section{Summary of System Control and Operation}

\subsection{System Control}

Fig. 9 shows the conceptual drawing of the control system. Data of the level sensors installed at the location of each climbing robot jack and action command to equipment and monitor signal are transmitted from and received by the local personal computer that is incorporated in each climbing robot jack and LAN on the central control board. At the central control board, the relative difference that appears on each level sensor is processed as information of difference in level and the control data to control this difference in level within the 
allowable range is transmitted to each local personal computer, based on which the local personal computer actuates the hydraulic unit and chuck, etc., that grip steel pipe to ascend or descend.

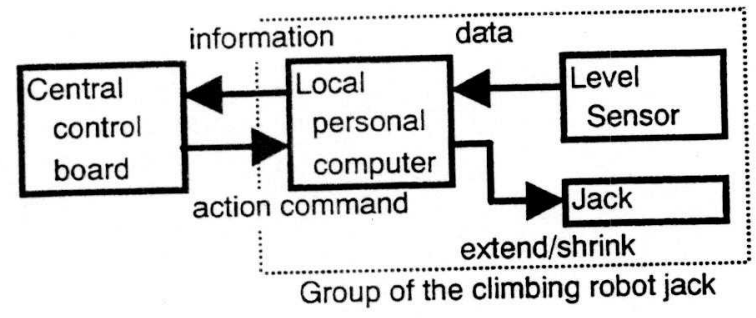

Fig. 9 Control system

The control of this system is performed with the central control board laid out on the climbing main frame as a host computer and by transmitting control command to the local personal computer in each climbing robot jack based on the input data from the touch panel display. Fig. 10 shows an example of touch panel display which indicates the difference in level. Fig. 11 shows an example of the situation of each climbing robot jack. Main input items and output items for control, are shown below.

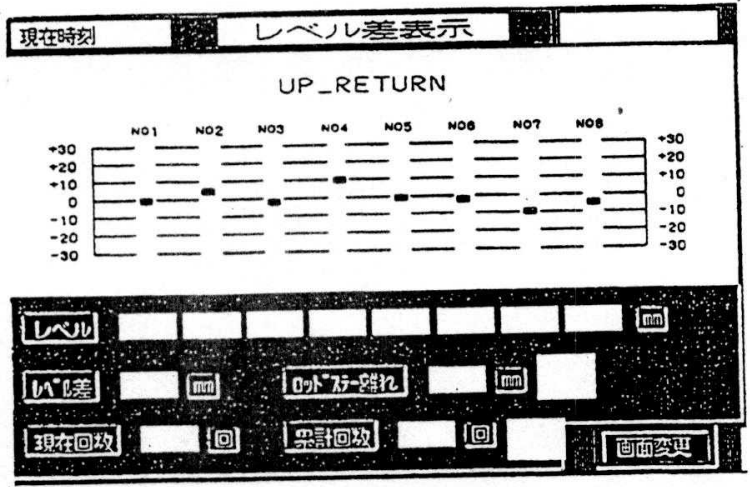

\section{Fig.10 Example of display}

\section{(1) Input items}

(1) Selection of automatic or manual

(2) Selection of ascending and descending

(3) Setting of allowable difference in level

(4) Setting of number of local personal computers

(5) Setting of number of operation times (number of actions)

(2) Output items

(1) Graphic display, data display and maximum difference in level of level data at each position

(2) Number of actions at present and total number of actions

(3) Graphic display of action condition of each climbing robot jack

(4) Stroke value and hydraulic pressure value of each climbing robot jack

(5) Situation of occurrence of trouble and measures and method therefor

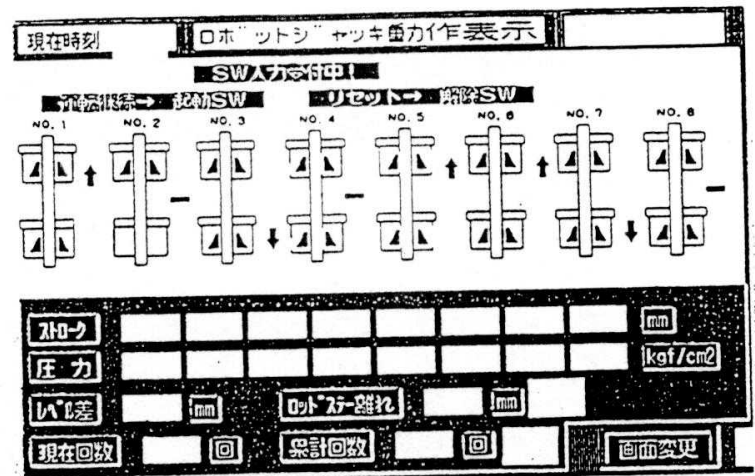

Fig.11 Example of display
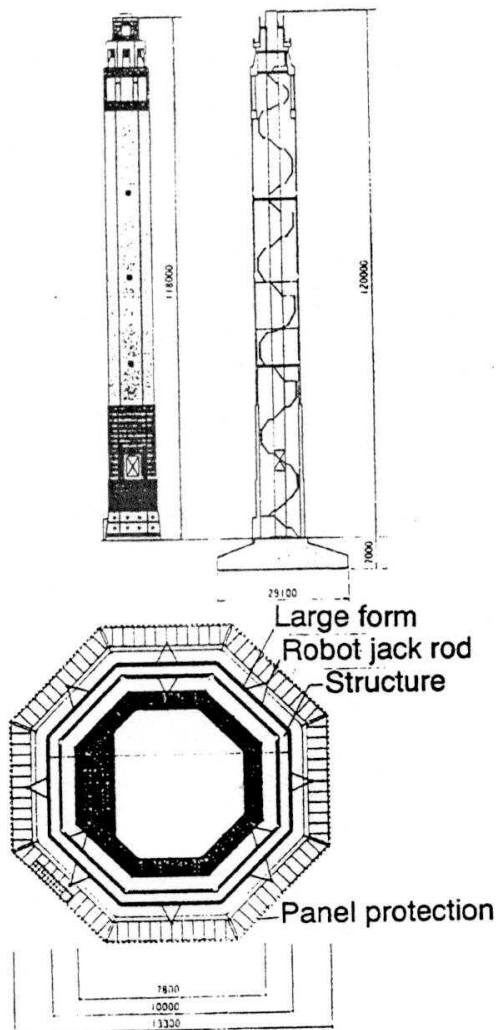

Fig.12 External of chimney

\subsection{Operation of System}

By pressing the touch panel of the central control panel and after confirming the input items and by pressing the starter button, the operation can be 
performed fully automatically. In case of the trouble, such as an emergency stop, etc., the cause and measures for recovery will be displayed by step making the maintenance easier.

\section{Construction}

This construction method was applied to the construction of a high-rise chimney as a final smoke exhaust system of the garbage treatment plant. The summary of construction and results are described below.

\subsection{Summary of Construction}

\section{(1) Subject of construction}

The summary of the chimney constructed using this system is described below and Fig. 12 shows the external shape drawing.

\section{Construction : $\mathrm{RC}$ construction \\ Shape : Right octagonal shape}

Major dimension: Height; 118m, Dimension to opposite side; $10.4 \mathrm{~m}$, Length of one side; $4.3 \mathrm{~m}$, Thickness of concrete; $0.8 \mathrm{~m}$

\section{(2) Construction facility}

Two sets of the climbing robot jacks were used for outside and inside the structure. As the system applicable to the perimeter of the structure was approximately $70 \mathrm{t}$ in gross load according to the plan, in consideration of capacity of the jack and the fact that the structure is the right octagonal shape, the climbing robot jack used were to be 1 set per 1 side, 8 sets in total.

As the system applied to the inner surface of the structure was approximately $20 t$ in gross load according

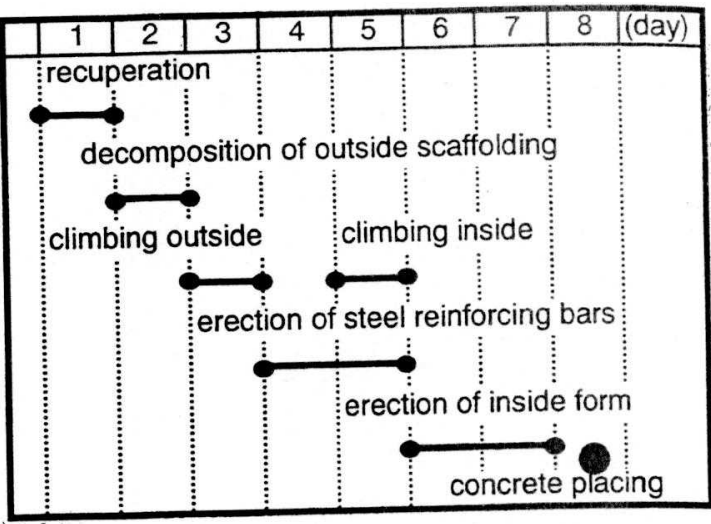

Fig.13 Cycle of construction

to the plan, in consideration of capacity of jack even though the structure is the right octagonal shape, 3 sets of the climbing robot jack were decided to be used. The position of the setting was also decided in consideration of the balance of load to be approximately the same on each set. They were to have the central control board, respectively and acts as a separate system.

\section{(3) Construction Procedure}

As a preparatory work prior to the commencement of construction using the FCF construction method 34 days in total were spent for a series of works.

After the preparatory work mentioned, construction of 1 lot (typical section $4.25 \mathrm{~m}$ in height) was repeated in cycle as shown in Fig. 13. The climbing action was performed using the climbing robot jack, which was set at the lowermost part of the all-weather type working space (house). To prevent the rod from buckling on the way, rod stay to fix the rod to the structure was installed at every $1.4 \mathrm{~m}$ and climbing of 1 lot was completed in
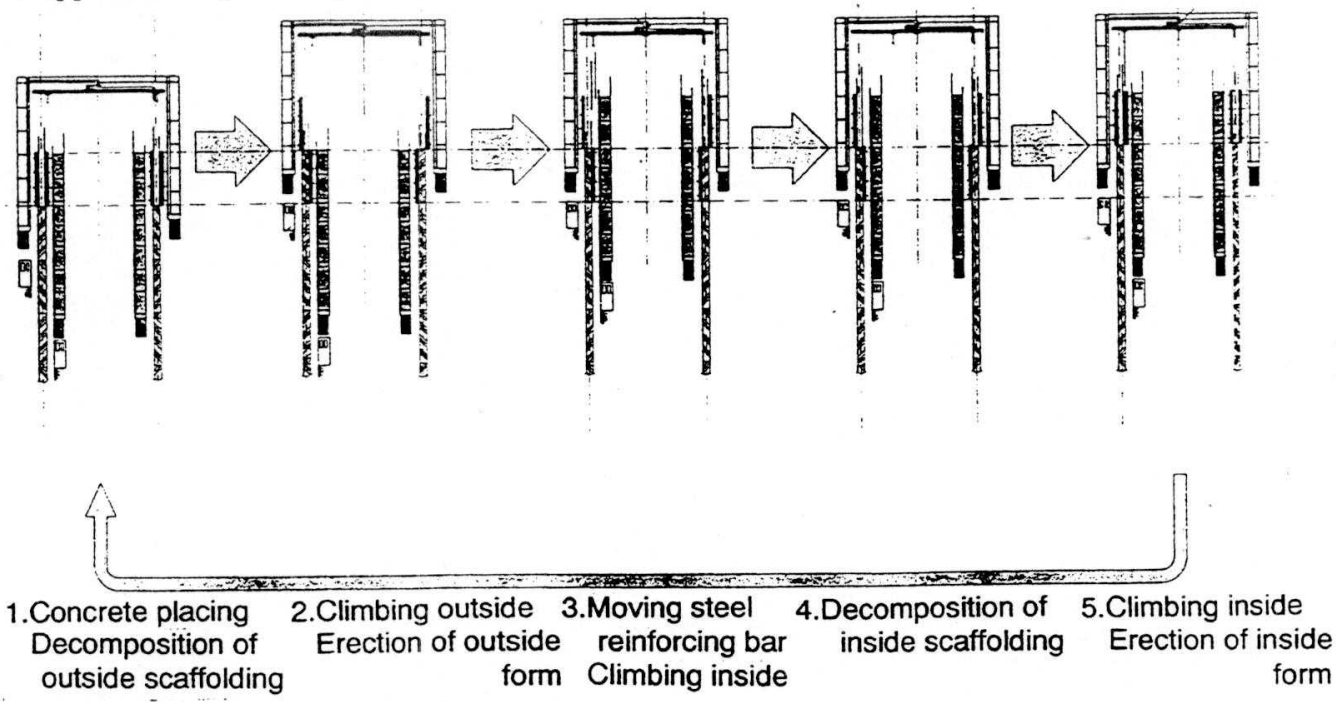

Fig.14 Construction procedure 
about 2 hours.

All-weather type working space and exterior scaffolding were ascended and subsequently, a series of operations including, stripping operation of the form, moving in of unitized steel reinforcing bars using conveyance flat car and the circle crane, erection, ascending of interior work scaffolding and the form and setting of the form, were performed prior to the placing of concrete.

Concrete placing was performed by pumping concrete from the ground by the concrete pump car and was efficiently distributed in the form on each side by means of the concrete distributor set on the ceiling of the all-weather house. Subsequently after elapse of curing period, the form was stripped. By repeating these cycles and after completing the final construction, the whole of the system was descended to the position where it was assembled in the preparatory work and disassembled. These construction procedure are shown in Fig. 14.

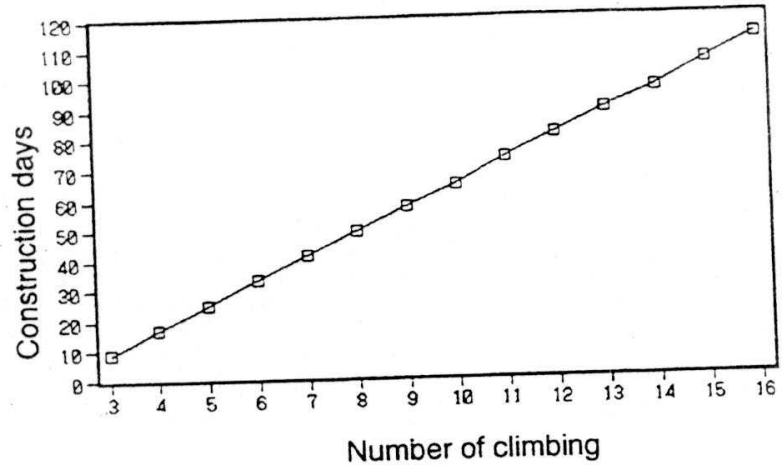

Fig.15 Construction days

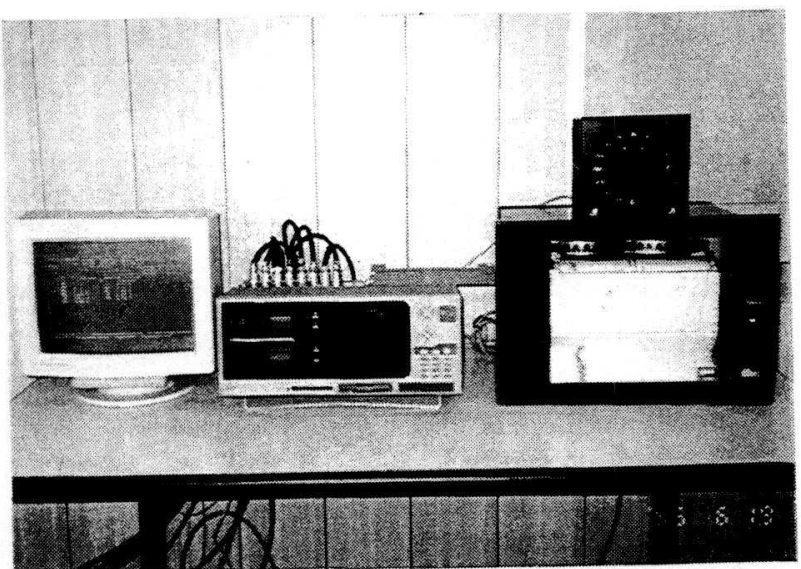

Fig.17 Situation of measurement

\subsection{Results of Construction}

(1) Schedule
The accumulated construction days using the FCF construction method were as shown in Fig. 15. There was almost no delay in the schedule due to machine troubles and the progress was smooth. Fig. 16 shows the situation of final construction.

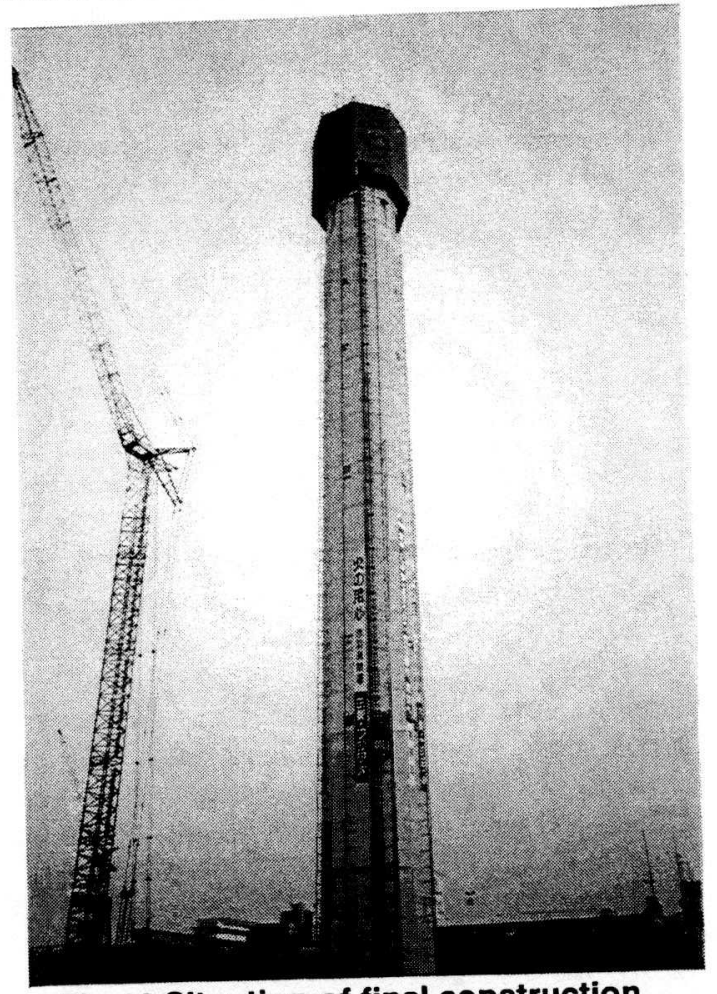

Fig.16 Situation of final construction

\section{(2) Wind load}

Wind load and axial force of rod were measured always. Fig. 17 shows the situation of measurement.

During the time when the work was at $60 \mathrm{~m}$ in height a typhoon had passed the site subjecting the structure to the wind load of $20 \mathrm{~m} / \mathrm{sec}$ for two hours with the maximum wind velocity of $23 \mathrm{~m} / \mathrm{sec}$. As a special measure, the all-weather type working space was tied to the chimney structure with a wire rope, but because of thorough examination against wind it was confirmed that there was no problems as a result.

\section{(3) Axial force of rod}

Each climbing robot jack when ascending (descending) the relative height is automatically controlled within the set difference in level (ordinary $15 \mathrm{~mm}$ ). Although the level stayed within the fixed range a delicate difference in level appeared as a difference in axial force of each rod. As an example of this Fig. 18 shows the distribution axial force of each rod at a certain point in time measured by the load cell, and Fig. 19 fluctuation of axial force of designated machines due to climbing (ascending). 
An increase in axial force, which was considered to be due to expansion by heat of the rod as a result of a rise in temperature, was recognized. These fluctuation ranges were within the scope that can clear the safety at the time of the design. As an example of this Fig. 20 shows the fluctuation of axial force due to temperature.

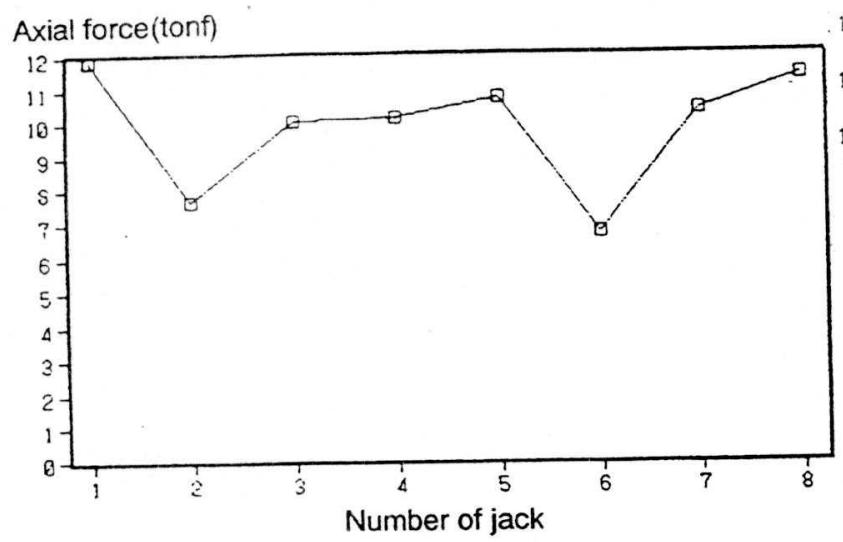

Fig.18 Example of axial force

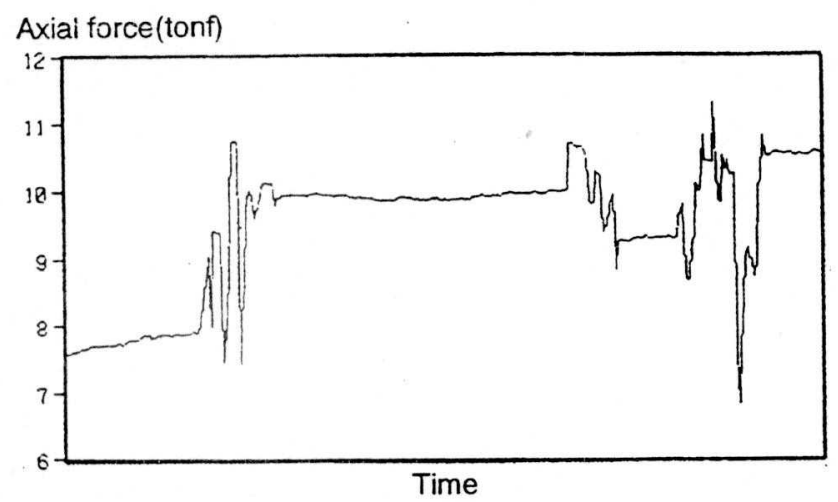

Fig.19 Example of axial force

\section{Conclusions}

To the FCF construction method with the climbing robot jack that has abundant experience in construction of tall pier as a nucleus, various new functions were added this time and it ended up to be a new system that can demonstrate the power in the construction of highrise chimneys.

Construction of a high-rise chimney with the height of $118 \mathrm{~m}$ was performed using this system. The following results were obtained:

(1) With the climbing robot jack as the nucleus and as a result of rational layout of various

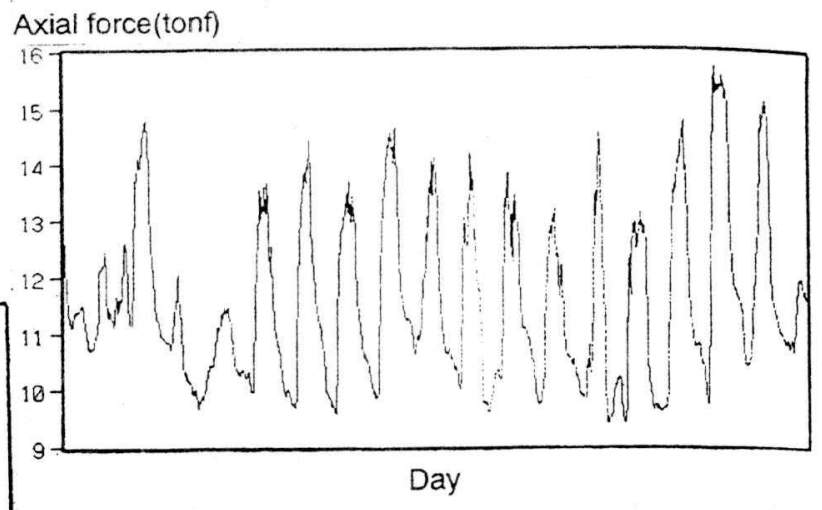

Fig.20 Example of axial force

construction equipment and devices as follows, a systematized working space was able to be realized:

- Climbing robot jack system

- Climbing working stage

- Large form

- Automatic open tent

- Circle crane

- Concrete distributor

- Steel reinforcing bar conveyance flat car

(2) Even though the work had to be performed at an elevated location, the work was completed safely.

(3) By realizing all-weather working space, work efficiency was improved.

(4) Shortening of construction period and manpower saving were realized.

At the end of completion of the actual construction this time, it was confirmed that this construction method can cope sufficiently with the construction of high-rise structure in excess of $100 \mathrm{~m}$ in height and that it was an effective method of construction.

In the future, we hope to be able to evolve this construction method broadly with high-rise pier and high-rise chimney as its center.

\section{References}

Kiyoshi Sato ,et al , "DEVELOPMENT AND APPLICATION OF CLIMBING ROBOT JACK SYSTEM" Proceedings of the 5 th International Symposium on Robotics in Construction, pp.477-482,1988. 